\begin{tabular}{l}
2 \\
\multirow{2}{\alpha}{} \\
$\vdots$ \\
$z$ \\
$\vdots$ \\
$\vdots$
\end{tabular}

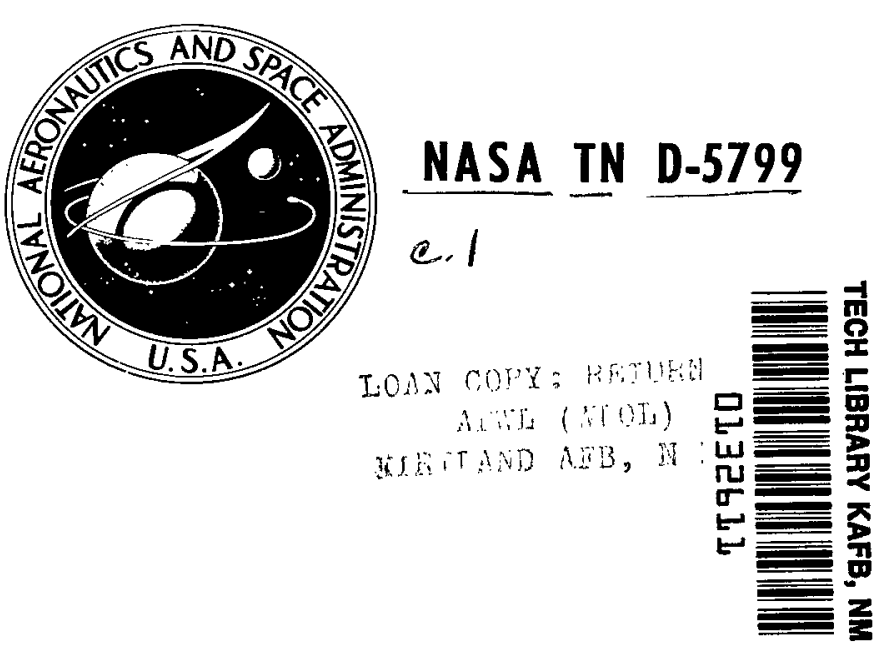

\title{
KINETIC STUDY OF FLUORINATION OF SILVER
}

by Patricia M. O'Donnell

Lewis Research Center

Cleveland, Obio 44135

NATIONAL AERONAUtics AND SPACE ADMINISTRATION - WASHINGTON, D. C. - MAY 1970 
1. Report No. NASA TN D-5799

4. Title and Subtitle KINETIC STUDY OF FLUORINATION OF SILVER

7. Author(s)

Patricia M. O'Donnell

9. Performing Organization Name and Address

Lew is Research Center

National Aeronautics and Space Administration Cleveland, Ohio 44135

12. Sponsoring Agency Name and Address National Aeronautics and Space Administration Washington, D. C. 20546

15. Supplementary Notes

16. Abstract

The kinetics of the reaction of fluorine with silver were studied at temperatures from $25^{\circ}$ to $300^{\circ} \mathrm{C}(298$ to $573 \mathrm{~K})$ and 50 - to 600 -toor $\left(6666-\right.$ to $\left.79993-\mathrm{N} / \mathrm{m}^{2}\right)$ fluorine pressure. The reaction is pressure dependent and can be described by the equation $y^{n}=k_{r} t+c$. Three products are identified: silver subfluoride, silver monofluoride, and silver difluoride. The calculated value of the diffusion constant is $0.10 \mathrm{~cm}^{2} / \mathrm{sec}$, and the activation energy for the diffusion process is $10 \mathrm{kcal} / \mathrm{mole}(41.8 \mathrm{~kJ} / \mathrm{mole})$. Silver ion vacancy migration is proposed as the diffusion mechanism. Reaction-rate constants are listed.

17. Key Words (SuBBested by Author(s)) Fluorination

Kinetics

Corrosion
18. Distribution Statement

Unclassified - unlimited

19. Security Classif. (of this report) Unclassified

20. Security Clossit. (of thi s page) Unclassified
21. No. of $P$ ages

20
22. Price* $\$ 3.00$

* For sale by the Clearinghouse for Federal Scientific and Technical Information Springfield, Virginia 22151 


\title{
KINETIC STUDY OF FLUORINATION OF SILVER
}

\author{
by Patricia M. O' Donnell \\ Lewis Research Center
}

\section{SUMMARY}

The effect of the variables temperature and pressure on the kinetics of the reaction of fluorine gas with silver was studied. The temperature range studied was $25^{\circ}$ to $300^{\circ} \mathrm{C}(298$ to $573 \mathrm{~K})$ at total fluorine pressures of 50 to 600 torr $\left(6666\right.$ to $\left.79993 \mathrm{~N} / \mathrm{cm}^{2}\right)$. The reaction was followed by the pressure-drop method and was found to be pressure dependent. The applicable rate law was $y^{n}=k_{r} t+c$, where $y$ is the amount of fluorine consumed per unit area of silver surface, $\mathrm{k}_{r}$ is the reaction-rate constant, $t$ is the time in minutes, and $\mathrm{c}$ is a constant. The value of $\mathrm{n}$ was 1 during the initial course of the reaction, indicating a boundary controlled process. At a later time, the process became diffusion controlled, where the value of $\mathrm{n}$ was 2. The reaction is complex due to the formation of three products: silver subfluoride, silver monofluoride, and silver difluoride. Rate constants are calculated, and activation energies are given. The reaction appears to be cation diffusion controlled, and the diffusion through the barrier layer is by a vacancy mechanism. The calculated value of the diffusion constant is 0.10 centimeter squared per second, and the activation energy for the diffusion is 10 kilocalories per mole $(41.8 \mathrm{~kJ} / \mathrm{mole})$.

\section{INTRODUCTION}

The reactivity of metals in a gaseous environment is a subject of interest to many people; for instance, the corrosion engineer, who is interested in the strength and durability of metals exposed to the atmosphere, the chemist, whose main interest is the chemical reactions that can occur between different metals and gases, and still others who are interested in the solid state properties of the system and the kinetics and mechanisms of the gas-solid reactions. Although the majority of studies that have appeared in the literature discuss the reactivity of metals in an oxygen environment, there have been some detailed studies on the reactivity of metals in a fluorine environment (refs. 1 to 15). The present investigation of the kinetics of the fluorination of silver was undertaken because 
the only data available in the literature merely describes this system in terms of the possible products of the chemical reactions with no data on the kinetics or mechanisms of the reaction. It is known from this previous work that three chemical reaction products are possible when silver combines with fluorine but it was not known what effect the kinetic variables of time temperature and pressure would have on the three silver fluorides. This report presents the results of a kinetic study of the fluorination of silver over the temperature range of $25^{\circ}$ to $300^{\circ} \mathrm{C}(298$ to $573 \mathrm{~K}$ ) and fluorine pressures of 50 to 600 tor $\mathrm{r}$ $\left(6666\right.$ to $79993 \mathrm{~N} / \mathrm{m}^{2}$ ) and considers a mechanistic model for the reaction.

\section{EXPERIMENT}

The system used to study the fluorination of silver is shown in figure 1. Fluorine is

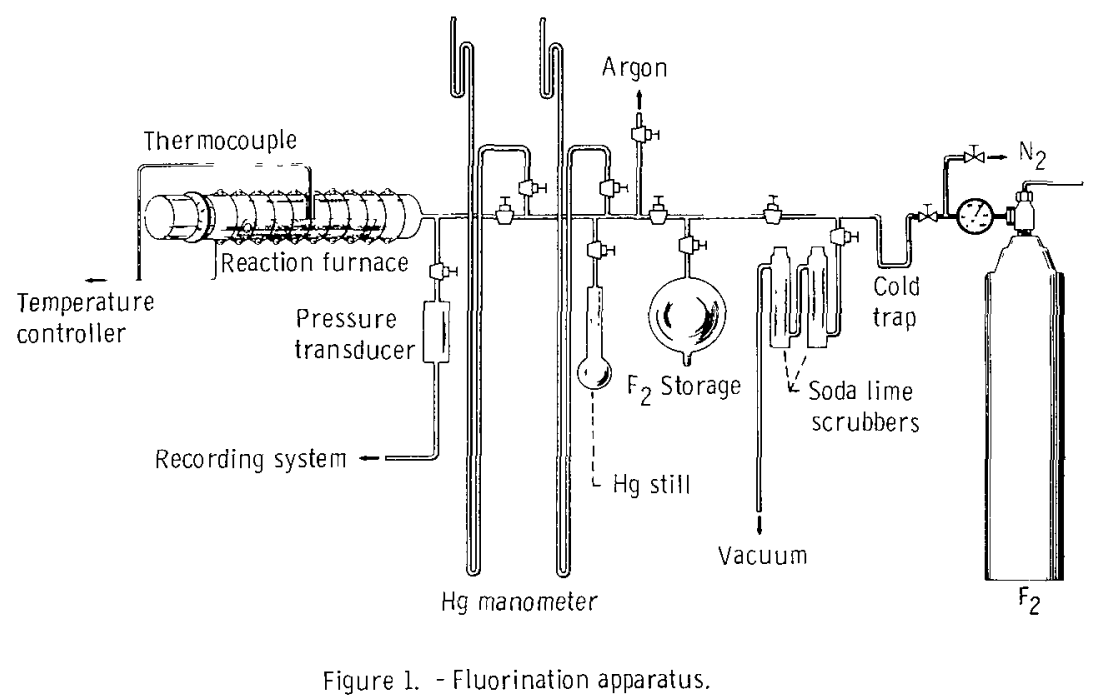

brought from the tank through copper tubing into the system, which is pyrex throughout except for the reaction furnace which is made of quartz. A cold $\left(-116^{\circ} \mathrm{C}, 157 \mathrm{~K}\right)$ trap using a methyl cyclohexane slush bath is used to remove hydrogen fluoride impurity from the fluorine. The fluorine is analyzed by reaction with mercury in the still (ref. 1). Analysis of the fluorine indicated 99.83-percent fluorine plus 0.17-percent HF before purification and 100-percent fluorine after purification. Enough purified fluorine for one run is stored in the storage bulb. The mercury manometers in the system indicate the pressures in the storage and reaction sections of the apparatus. A layer of fluorocarbon oil is floated on top of the mercury to prevent it from reacting with the fluorine. All readings are corrected for density differences between the oil and the mercury. The 
metal samples are silver plates 1.27 by 15.24 by 0.012 centimeter. Spectrographic analysis gave a purity of 99.999 percent.

A plate is inserted into the cold reaction furnace under flowing argon and is positioned upright in the center of the furnace. The end plug is put in place and the argon pumped out. The furnace is turned on and the reaction section brought up to the appropriate temperature. Temperature profiles have been run with an instrumented metal sample, and the results show that the temperature variation across the sample is not more than $1^{\circ} \mathrm{C}$. Meanwhile the storage section is filled with fluorine. The general experimental method used to determine the rate of fluorine consumption by silver is to measure the pressure decrease in a vessel of known volume containing the silver sample. In order to maintain approximately constant fluorine pressure, the pressure is allowed to drop only about 2 torr, and then more fluorine is introduced to return the pressure to its initial value. Pressures are recorded automatically by the pressure transducer and recording system. The perfect-gas law is used to calculate the amount of fluorine consumed from the incremental pressure drop, the vessel volume, and the temperature. From the calibrated volume ${ }^{\prime}\left(666^{2}\right.$ system, pressure changes on the time trace can be converted to milliliters of fluorine consumed at standard temperature and pressure (STP). After approximately a 4-hour exposure time, the heaters are turned off, the system is allowed to cool to $25^{\circ} \mathrm{C}(298 \mathrm{~K})$, and then the fluorine is pumped out of the system through the two soda lime scrubbers. The system is then brought up to atmospheric pressure with argon. A dry box is connected to the end of the furnace, and the sample is pulled into it under flowing argon to prepare it for chemical and instrumental analysis.

\section{RESULTS AND DISCUSSION}

\section{Kinetics of Reaction}

The kinetics of the fluorination of silver were determined at several temperatures and pressures. The fluorine reaction was followed as a function of time and is reported as milliliters of fluorine consumed at STP per square centimeter of silver surface based upon the geometrical area of the silver surface.

The effect of temperature on the reaction at constant fluorine pressures of 50 and 200 torr ( 6666 and $26664 \mathrm{~N} / \mathrm{m}^{2}$ ) is shown in figures $2(\mathrm{a})$ and (b), respectively. Analysis of these curves indicates that no simple rate law will describe the silver-fluorine system. The data can best be described by an exponential rate law, $y^{n}=k_{x} t+c$, where $y$ is the amount of fluorine consumed per square centimeter of silver surface, $t$ is the time in minutes, $k_{r}$ is the reaction-rate constant in (milliliters) ${ }^{n}$ (centimeters) $^{-2 n}$ ${\text { (minutes })^{-1} \text {, and } \mathrm{c} \text { is a constant in (milliliters) }}^{\mathrm{n}}$ (centimeters) $^{-2 \mathrm{n}}$. The reaction was run at $300^{\circ} \mathrm{C}(573 \mathrm{~K})$, but the data were very erratic due to burning and melting of the sample and they are not plotted. The effect of pressure on the reaction at constant tem- 


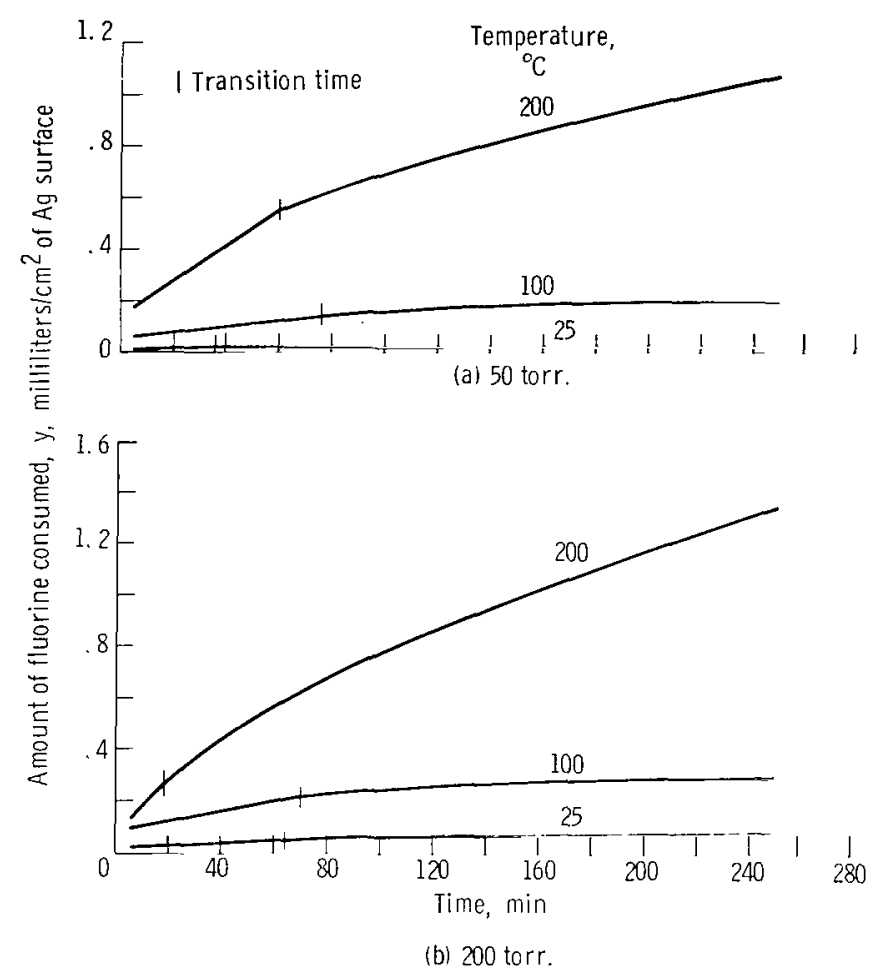

Figure 2. - Temperature effect at 50- and 200 -torr fluorine pressure.

peratures of $100^{\circ}$ and $200^{\circ} \mathrm{C}(373$ and $473 \mathrm{~K})$ is shown in figures $3(\mathrm{a})$ and $(\mathrm{b})$, respectively. Note that at both temperatures there is a pressure reversal. The change in the effect of pressure on the reaction is attributed to a change in product formation. This observed reversal in pressure dependency is not unique to this system but has been observed in other fluorination studies where multiple products are formed.

The data were analyzed by computer, applying the method of Hudson (ref. 15). A program was written for a linear-quadratic fit. Reaction-rate constants were calculated from the slopes of the lines and are listed in table I for the various temperature and pressure ranges studied. Data were not obtained at $t=0$, the initial contact time of fluorine with the silver, because it takes a finite period of time to pressurize the apparatus with fluorine.

The value of $n$ indicates the process or processes which are controlling the reaction (refs. 16 and 17 ). If $n=1$, the rate controlling process would be a boundary-layer process to be discussed later. If $\mathrm{n}=2$, the reaction would be controlled by a diffusion process. For the silver-fluorine reaction, the value of $n$ is not constant over the entire time interval but goes from 1 to 2 as time increases, indicating that the reaction is initially a boundary controlled process which at a later time becomes diffusion controlled. An example of the linear portion is shown on an expanded scale in figure $4(a)$ and that of the parabolic region in figure $4(\mathrm{~b})$. 


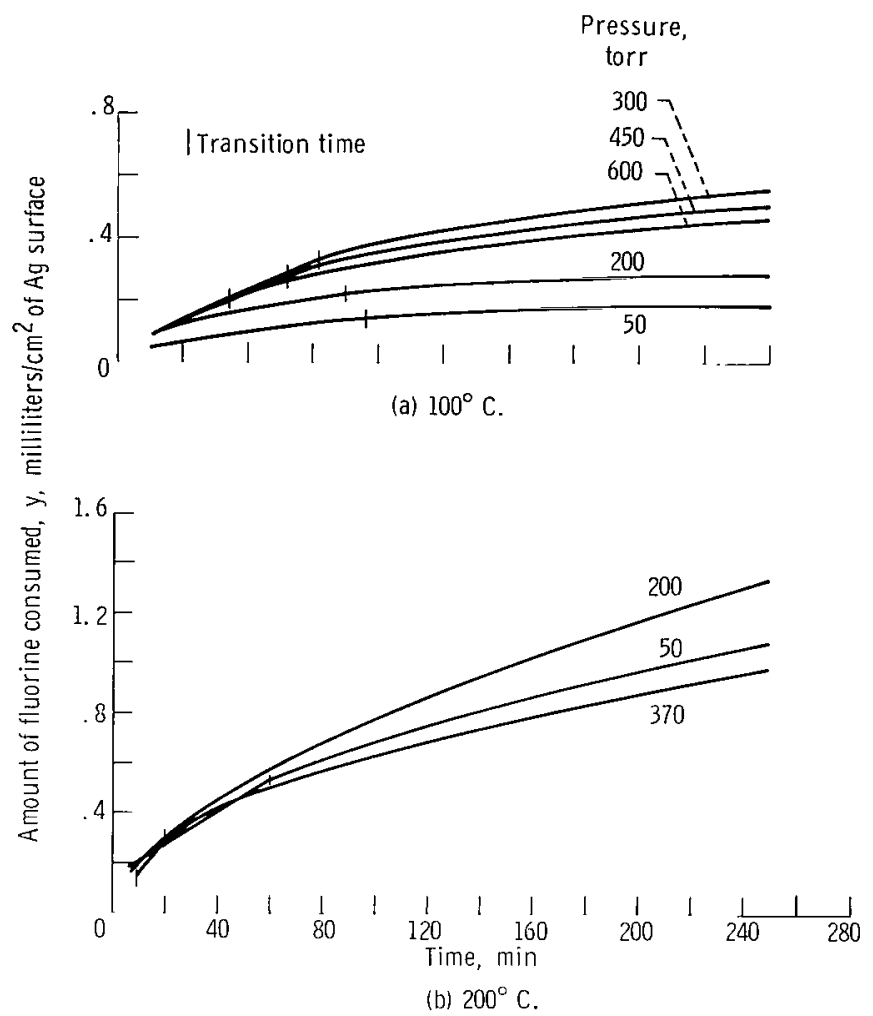

Figure 3. - Pressure effect at $100^{\circ}$ and $200^{\circ} \mathrm{C}$.

TABLE I. - CALCULATED LINEAR ${ }^{\mathrm{a}}$ AND PARABOLIC ${ }^{\mathrm{b}}$ RATE CONSTANTS

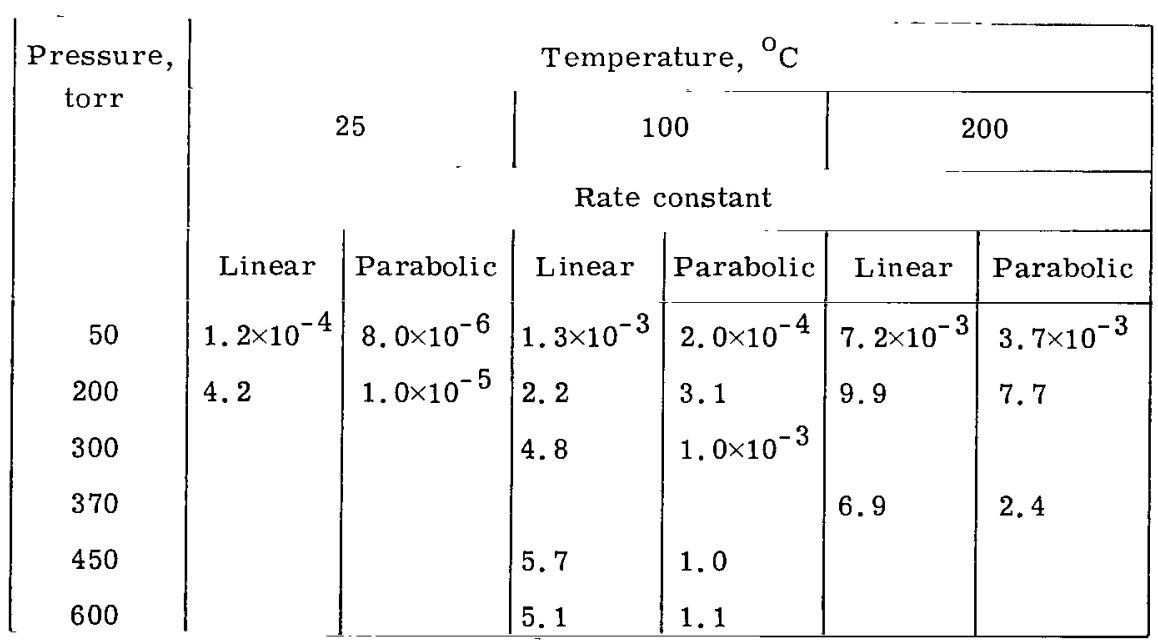

${ }^{\mathrm{a}}$ In milliliters per square centimeter per minute.

$b_{\text {In milliliters squared per centimeter }}{ }^{4}$ per minute. 

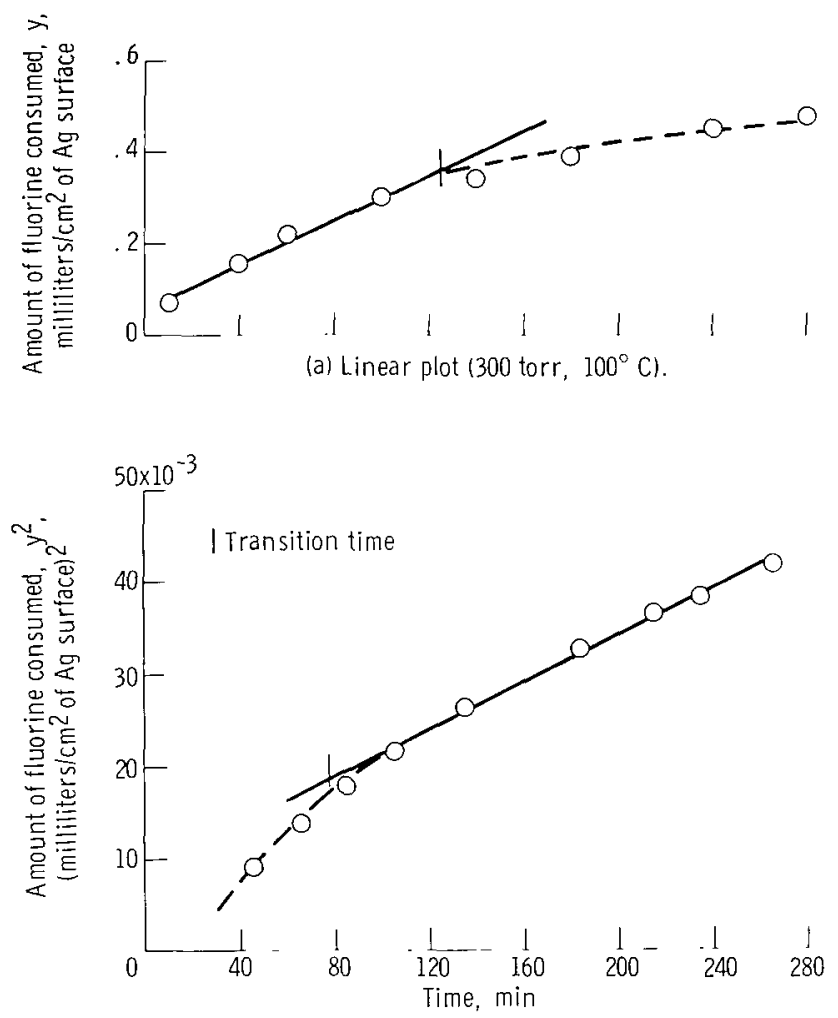

(b) Parabolic plot (50 torr, $100^{\circ} \mathrm{C}$ ).

Figure 4. - Linear and parabolic plots of fluorine consumption.

\section{Product Formation}

The silver-fluorine system is a complex system due to the formation of several reaction products. They are silver subfluoride $\left(\mathrm{Ag}_{2} \mathrm{~F}\right)$, silver monofluoride $(\mathrm{AgF})$, and silver difluoride $\left(\mathrm{AgF}_{2}\right)$. One or more of these products are observed at various temperature and pressure conditions. Silver subflouride appears as one of the reaction products even at temperatures above its reported decomposition temperature range $\left(90^{\circ}\right.$ to $200^{\circ} \mathrm{C}, 363$ to $\left.473 \mathrm{~K}\right)$. The products observed at various conditions are shown in table $\Pi$. The products were identified by X-ray diffraction, and by chemical and physical analyses. Some of the physical properties of the silver-fluorides are listed in table III. Where several products were identified, the films were always layered, with the fluoride richest in silver adjacent to the metal and the one richest in fluorine at the gas-fluoride surface. The monofluoride was found as the middle layer. The relative 
TABLE II. - PRODUCT FORMATION

\begin{tabular}{|c|c|c|c|c|}
$\begin{array}{c}\text { Pressure } \\
\text { torr }\end{array}$ & \multicolumn{4}{|c|}{ Temperature, ${ }^{\circ} \mathrm{C}$} \\
50 & 25 & 100 & 200 & 300 \\
\hline 100 & $\mathrm{Ag}_{2} \mathrm{~F}$ & $\mathrm{Ag}_{2} \mathrm{~F}, \mathrm{AgF}$ & $\mathrm{Ag}_{2} \mathrm{~F}, \mathrm{AgF}$ & \\
200 & $\mathrm{Ag}_{2} \mathrm{~F}$ & $\mathrm{Ag}_{2} \mathrm{~F}, \mathrm{AgF}, \mathrm{AgF}_{2}$ & $\mathrm{Ag}_{2} \mathrm{~F}, \mathrm{AgF}, \mathrm{AgF}_{2}$ & \\
300 & & $\mathrm{AgF}, \mathrm{AgF}_{2} \mathrm{~F}, \mathrm{AgF}, \mathrm{AgF}_{2}$ & Burned, melted \\
370 & & & $\mathrm{AgF}_{2}$ & \\
450 & & $\mathrm{AgF}, \mathrm{AgF}_{2}$ & $\mathrm{AgF}_{2}$ & \\
600 & & $\mathrm{AgF}, \mathrm{AgF}_{2}$ & & \\
\hline
\end{tabular}

TABLE II. - SOME PHYSICAL PROPERTIES OF SILVER FLUORIDES

\begin{tabular}{|c|c|c|c|}
\hline Property & $\mathrm{Ag}_{2} \mathrm{~F}$ & $\mathrm{AgF}$ & $\mathrm{AgF}_{2}$ \\
\hline $\begin{array}{l}\text { Crystal } \\
\text { structure }\end{array}$ & $\begin{array}{l}\text { Successive layers of } \\
\mathrm{AgF} \text { and } \mathrm{Ag}\left(\mathrm{CdI}_{2}\right. \\
\text { type); hexagonal } \\
\text { layered }\end{array}$ & $\begin{array}{l}\text { Cubic (NaCl type); } \\
\text { one side; } 4.92 \AA\end{array}$ & Monoclinic \\
\hline $\mathrm{H}_{2} \mathrm{O}$ stability & $\begin{array}{l}\text { Decomposes; stable } \\
\text { when dry }\end{array}$ & Soluble; hygroscopic & $\begin{array}{l}-\mathrm{Ag}_{2} \mathrm{O}+\mathrm{O}_{3}+\mathrm{HF} ; \\
\text { hygroscopic }\end{array}$ \\
\hline Conductivity & Electronic & Ionic & Ionic \\
\hline Distance $e^{a}$ & $\begin{array}{l}\mathrm{Ag} \underset{\stackrel{2.86 \stackrel{\AA}{\longrightarrow}}{\stackrel{2}{2}} \mathrm{Ag}}{\mathrm{Ag}} \mathrm{F}\end{array}$ & $\mathrm{Ag} \stackrel{2.46 \stackrel{\AA}{\longrightarrow}}{\longrightarrow} \mathrm{F}$ & Unknown \\
\hline Light effect & $\begin{array}{l}\text { Questionable, } \\
\text { probably none }\end{array}$ & $-\mathrm{Ag}_{2} \mathrm{~F}$ & None \\
\hline Color & Green & Yellow & Dark brown \\
\hline Special remarks & $\begin{array}{l}\text { Formed by } \mathrm{F}^{-} \\
\text {inserted in } \mathrm{Ag} \text { lat- } \\
\text { tice, not by } \mathrm{Ag} \text { in } \\
\mathrm{AgF} \text { lattice }\end{array}$ & & \\
\hline
\end{tabular}

${ }^{a}$ Radius of $\mathrm{Ag}, 1.53 \AA$. 
amounts of each product in the film, obtained from cross-section microscopy are shown in figure 5 for two pressures as a function of temperature. The amount of $\mathrm{Ag}_{2} \mathrm{~F}$ is shown by the circular symbols. As the temperature increases the amount of $\mathrm{Ag}_{2} \mathrm{~F}$ decreases. At $25^{\circ} \mathrm{C}(298 \mathrm{~K})$, only $\mathrm{Ag}_{2} \mathrm{~F}$ is formed at both pressures. The amount of $\mathrm{AgF}$, shown by the square symbols, seems to increase to a maximum amount and then decrease as the temperature increases. The amount of $\mathrm{AgF}_{2}$ is shown by the diamond symbols. No $\mathrm{AgF}_{2}$ is formed at 50 torr $\left(6666 \mathrm{~N} / \mathrm{m}^{2}\right)$ regardless of the temperature,

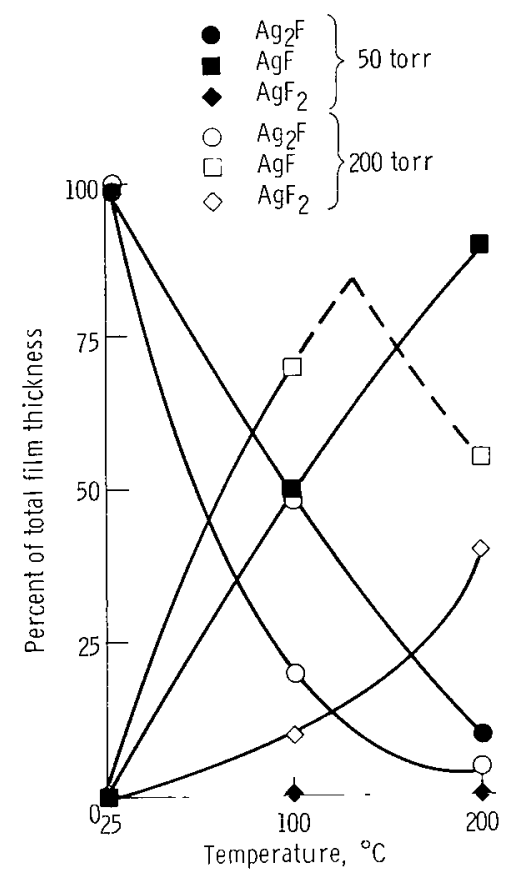

Figure 5. - Relative amounts of each product in the $\mathrm{i} i \mathrm{~lm}$.

$$
\begin{gathered}
\begin{array}{c}
\text { Temperature } \\
\text { increasing }
\end{array} \\
25^{\circ} \mathrm{C} \\
\qquad \begin{array}{ll}
\text { (a) } 4 \mathrm{Ag}+\mathrm{F}_{2} \rightarrow 2 \mathrm{Ag}_{2} \mathrm{~F} \\
& \text { (b) } \mathrm{Ag}_{2} \mathrm{~F} \rightarrow \mathrm{Ag}+\mathrm{AgF} \\
& \text { (c) } 2 \mathrm{Ag}_{2} \mathrm{~F}+\mathrm{F}_{2} \rightarrow 4 \mathrm{AgF} \\
& \text { (d) } 2 \mathrm{Ag}_{2} \mathrm{~F}+3 \mathrm{~F}_{2} \rightarrow 4 \mathrm{AgF}_{2} \\
& \text { (e) } 2 \mathrm{AgF}+\mathrm{F}_{2} \rightarrow 2 \mathrm{AgF}_{2} \\
& \text { (f) } 2 \mathrm{Ag}+\mathrm{F}_{2} \rightarrow 2 \mathrm{AgF} \\
200^{\circ} \mathrm{C} & \text { (g) } \mathrm{Ag}+\mathrm{F}_{2} \rightarrow \mathrm{AgF}_{2}
\end{array}
\end{gathered}
$$

Figure 6. - Some reactions of silver and fluorine, listed according to probability of occurrence with increasing temperature. 
while at 200 torr $\left(26664 \mathrm{~N} / \mathrm{m}^{2}\right)$ the amount increases as the temperature is increased. The reactions to consider are listed in figure 6 . They are arranged, according to reported data in the literature, by increasing probability of occurrence with increasing temperature. Not only temperature but also pressure affects the products formed. At $25^{\circ} \mathrm{C}$ and all pressures studied, the only product formed was the subfluoride $\mathrm{Ag}_{2} \mathrm{~F}$. However, as the temperature is increased, one or more reactions are possible, including the decomposition of the subflouride. At $300^{\circ} \mathrm{C}$, the product melted even through the temperature was well below the reported melting points of the monofluoride $\left(435^{\circ} \mathrm{C}\right.$, $708 \mathrm{~K}$ ) and the difluoride $\left(690^{\circ} \mathrm{C}, 963 \mathrm{~K}\right)$. This could be due to the formation of a known low melting eutectic $\mathrm{AgF} \cdot \mathrm{AgF}_{2}$ (ref. 18).

\section{Analysis of Reaction}

To obtain a primary understanding of the reaction between silver and fluorine, the products formed will be analyzed by the physical concept of volume ratios. It should be remembered that it is merely a guide and there are exceptions. Comparison of oxygen as an oxidizer and fluorine as an oxidizer can be made by considering the activation energies involved. Since heterogeneous systems can encompass two areas of mechanistic processes, boundary control and diffusion control, each of these will be discussed separately. Available diffusion data will be compared with calculated data for this system. From these analyses, the most probable reaction path is discussed.

\section{Volume Ratios}

It is important in the study of metal-gas reactions to determine whether the films formed in the reaction are protective or nonprotective. Analysis of volume ratios can give some insight into this problem.

In 1923, Pilling and Bedworth (ref. 19) defined the following equation for the molecular volume ratio $\varphi$ :

$$
\varphi=\frac{W d}{w D}
$$

where $W$ is the molecular weight of the substance formed adjacent to the reactive environment and $\mathrm{D}$ is its density, and $\mathrm{w}$ is the molecular weight of the underlying layer and $\mathrm{d}$ is its density.

Values of molecular volume ratios less than 1 indicate that the film is unprotective. Molecular volume ratios much greater than 1 generally indicate that the film might not be 
protective due to stresses, while molecular volume ratios in the intermediate range are indicative of protective films (ref. 15). Application of this formula to the products formed in the silver-fluorine reaction must take into account the layering effect. Therefore, the molecular volume of the product in each case is not referred to silver since, except in the case of the subfluoride, all other products are layered and are referred to the molecular volume of the layer on which they are formed. For the formation of $\mathrm{Ag}_{2} \mathrm{~F}$ on silver, $\varphi=2.67$. The ratio for the monofluoride forming on the subfluoride is $\varphi=0.79$. The difluoride forming on the monofluoride gives a molecular volume ratio $\varphi=1.46$. According to the possible reactions at high temperatures and pressures, the difluoride could form directly on the silver, and the molecular volume ratio for this would be $\varphi=3.1$. Both protective and nonprotective films can form when fluorine and silver react. It should be remembered that the Pilling-Bedworth ratio is only a guide and there are exceptions. It is believed that the reaction follows a linear rate law in the temperature range $25^{\circ}$ to $100^{\circ} \mathrm{C}\left(298\right.$ to $373 \mathrm{~K}$ ) where $\mathrm{Ag}_{2} \mathrm{~F}$ is forming according to the equation $4 \mathrm{Ag}+\mathrm{F}_{2} \longrightarrow 2 \mathrm{Ag}_{2} \mathrm{~F}$. This is called the boundary controlled region and is defined as the region where the reacting gas has direct access to the reaction surface. As the nonprotective $\mathrm{Ag}_{2} \mathrm{~F}$ builds up and other fluorides form, reactions (b), (c), and (d) of figure 6 become important. For example, the formation of a protective AgF ${ }_{2}$ Iayer could force the reaction into the diffusion controlled region, with the reaction following a parabolic law. The transition time from boundary control to diffusion control would decrease with both an increase in temperature at constant pressure and an increase in pressure at constant temperature. The pressure effect on estimated transition times is shown in figure 7 .

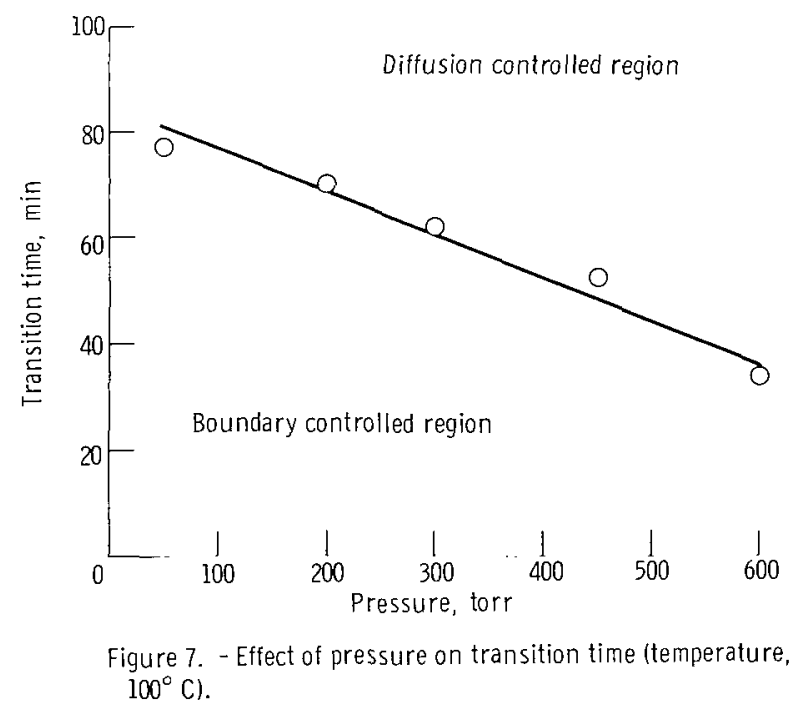



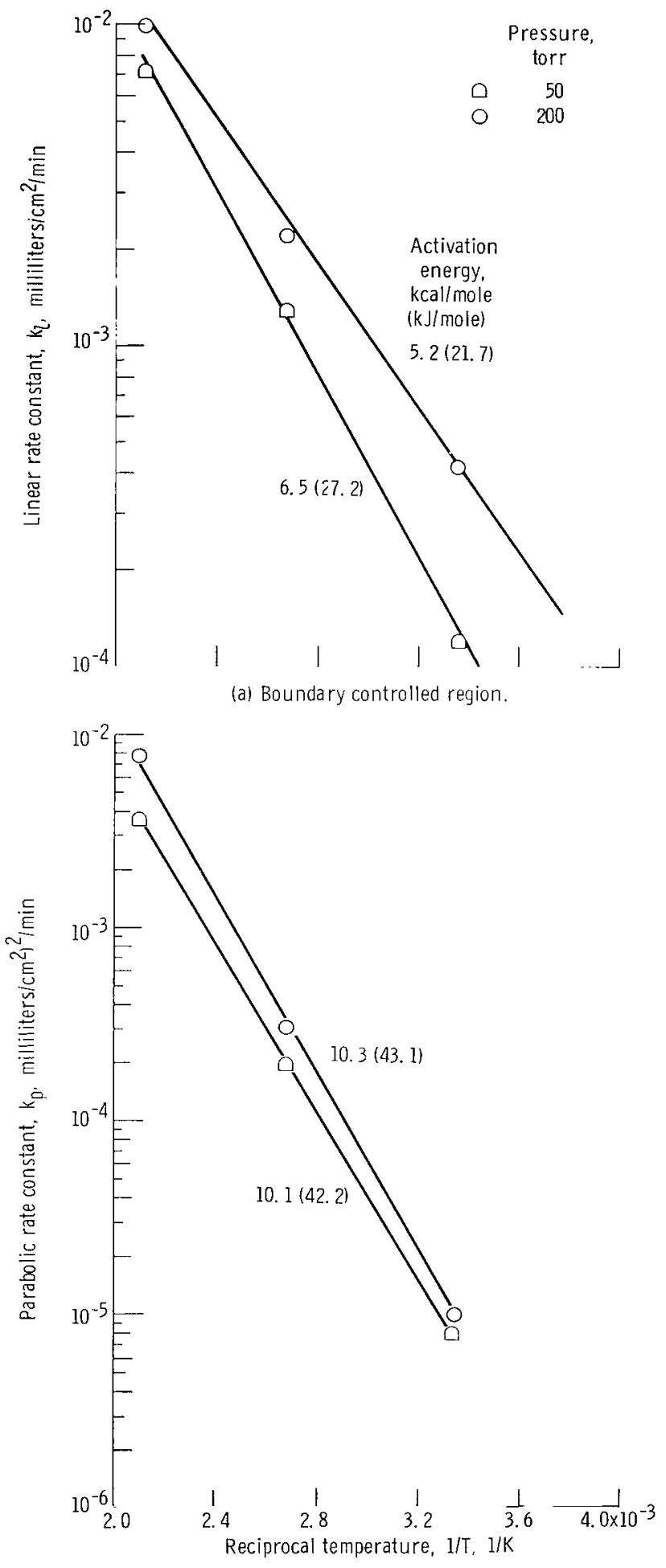

(b) Diffusion controlled region.

Figure 8. - Effect of temperature on rate constant in diffusion controlled and boundary controlled regions. 


\section{Activation Energy}

The reaction between fluorine and silver follows the Arrhenius equation

$$
\log \mathrm{k}_{\mathrm{r}}=-\frac{\Delta \mathrm{H}}{2.303 \mathrm{R}} \frac{1}{\mathrm{~T}}
$$

This is seen in figure $8(\mathbf{a})$ where the linear reaction-rate constants are plotted against $1 / \mathrm{T}$ and in figure $8(\mathrm{~b})$ where the parabolic rate constants are plotted in the same manner. The data in figure 8(a) indicate there is a pressure effect. At 200 torr (26 664 $\left.\mathrm{N} / \mathrm{m}^{2}\right)$, the calculated activation energy is $5.2 \mathrm{kilocalories} \mathrm{per} \mathrm{mole}(21.7 \mathrm{~kJ} / \mathrm{mole})$, while at 50 torr $\left(6666 \mathrm{~N} / \mathrm{m}^{2}\right)$ it is 6.5 kilocalories per mole $(27.2 \mathrm{~kJ} / \mathrm{mole})$. The data in figure $8(\mathrm{~b})$ do not show a pressure effect since the activation energy is approximately $10 \mathrm{kilocalories} \mathrm{per} \mathrm{mole}(41.8 \mathrm{~kJ} / \mathrm{mole})$ at both pressures. Brown and Crabtree (ref. 1) observed a pressure effect on the activation energy but could offer no explanation.

If we consider only the diffusion controlled portion of the reaction, we know that for the reaction to continue once a protective layer forms, movement of some species must take place across this layer. The silver halides are known ionic conductors. Transference number measurements in the literature on $\mathrm{AgCl}$ and $\mathrm{AgBr}$ indicate that silver ion is predominately the migrating species. The literature values of the activation energy for the mobility of the silver ion in these silver halides $(6.5 \mathrm{kcal} / \mathrm{mole}(27.2$ $\mathrm{kJ} / \mathrm{mole}$ ) for $\mathrm{AgCl}$ and $8.2 \mathrm{kcal} / \mathrm{mole}(34.3 \mathrm{~kJ} / \mathrm{mole}$ ) for $\mathrm{AgBr}$ (ref. 20)) and our calculated activation energy $(10 \mathrm{kcal} / \mathrm{mole}(41.8 \mathrm{~kJ} / \mathrm{mole})$ ) for the silver-fluorine reaction in the diffusion region are the same order of magnitude. It is proposed that in the silverfluorine reaction diffusion through the protective fluoride layer is controlled by silver ion diffusion.

\section{Boundary Controlled Processes}

The reaction was determined to be initially boundary controlled. When the clean metal surface is exposed to the fluorine gas, the reaction takes place initially at the gasmetal interface. If the product formed is volabile, then the fluorine will continue to react at the metal surface. If, however, nonvolatile products are formed on the surface, they can inhibit the gas from having direct access to the metal surface. Films of lower molecular volume than the substrate could be porous and nonprotective and would not inhibit the gas from having direct access to the metal. In these cases, the reaction would remain boundary controlled. 


\section{Diffusion Processes}

Diffusion of species through a barrier layer can take place by either diffusion of point defects through the lattice or diffusion along grain boundaries or dislocations. It has been shown by Zener (ref. 21) that one can differentiate between diffusion of point defects through the lattice and diffusion along grain boundaries or dislocations by taking into account an entropy factor.

The defect equation representing the formation of silver difluoride is given by equation (3)

$$
\mathrm{F}_{2}(\mathrm{~g}) \rightleftarrows 2 \mathrm{~F}^{-}+\underset{\text { Cation vacancy }}{+}+\underset{2 \oplus}{\text { Positive hole }}
$$

The entropy calculation can be used to test a proposed mechanism. Let us apply this to the silver-fluorine system.

Vacancy diffusion involves two processes: the formation of the vacancy and mobility of the vacancy. The total heat and entropy of the reaction can be expressed by

$$
\Delta \mathrm{H}_{\text {total }}=\Delta \mathrm{H}^{\mathrm{O}}+\Delta \mathrm{H}^{*}
$$

where

$\Delta \mathrm{H}^{\mathrm{O}} \quad$ energy of formation of vacancy

$\Delta \mathrm{H}^{*} \quad$ energy of movement of vacancy

and

$$
\Delta S_{\text {total }}=\Delta S^{O}+\Delta S^{*}
$$

where

$\Delta S^{\mathrm{O}} \quad$ entropy of formation of vacancy

$\Delta \mathrm{S}^{*} \quad$ entropy of movement of vacancy

The total activation energy is known for the reaction from the Arrhenius plot. The total entropy of the reaction can be calculated by transition state theory

$$
\mathrm{k}_{\mathrm{r}}=A \mathrm{e}^{\Delta \mathrm{S} / \mathrm{R}} \mathrm{e}^{-\Delta \mathrm{H} / \mathrm{RT}}
$$


where $\mathrm{k}_{\mathrm{r}}$ is the reaction-rate constant, $\mathrm{R}$ is the gas constant in calories per degree per mole, and $T$ is the temperature in $K$. The quantity $A$ contains a lattice distance factor and a temperature dependent term (ref. 22). Expanding equation (6) we get equation (7)

$$
\mathrm{k}_{\mathrm{r}}=2 \lambda^{2} \frac{\mathrm{kT}}{\mathrm{h}} \exp \left(\frac{\Delta \mathrm{S}^{\mathrm{O}}+\Delta \mathrm{S}^{*}}{\mathrm{R}}\right) \exp \left(\frac{\Delta \mathrm{H}^{\mathrm{O}}+\Delta \mathrm{H}^{*}}{\mathrm{RT}}\right)
$$

Upon rearranging we get

$$
\Delta S^{\mathrm{O}}+\Delta S^{*}=R\left[\ln \left(\mathrm{k}_{\mathrm{r}} \mathrm{h}\right)-\ln \left(2 \mathrm{kT} \lambda^{2}\right)\right]+\frac{\Delta \mathrm{H}^{\mathrm{O}}+\Delta \mathrm{H}^{*}}{\mathrm{~T}}
$$

where

$\lambda \quad$ jump distance between sites, $2.86 \times 10^{-8} \mathrm{~cm}^{\mathrm{a}}$

$\mathrm{k}$ Boltzmann constant, $1.38 \times 10^{-16} \mathrm{erg} / \mathrm{K}$

h Planck constant, $6.6 \times 10^{-27}$ erg-sec

Using equation (5) and the experimental value of $\Delta \mathrm{H}^{\mathrm{O}}+\Delta \mathrm{H}^{*}$ from the Arrhenius plot we can calculate the total entropy term. At $298 \mathrm{~K}$, we obtain

$$
\Delta S_{\text {total }}=\Delta S^{O}+\Delta S^{*}=+33.1 \mathrm{eu}
$$

The entropy of movement of a silver cation vacancy can now be estimated as follows. The entropy of silver difluoride at $298 \mathrm{~K}$ is $+22.5 \mathrm{eu}$. The entropy of the two fluoride ions in silver difluoride, assuming equal distribution ( $r$ ef. 24) between silver and fluorine, is two-thirds of this value, or $+15.0 \mathrm{eu}$. The entropy of fluorine at $298 \mathrm{~K}$ is +48.4 eu (ref. 25). For equation (3) then, the entropy change is $-33.4 \mathrm{eu}$. This has been calculated by assuming that no lattice distortion occurred when the vacancy was formed. Since a total of three defects was formed, one cation vacancy and two positive holes, and assuming equal entropy of formation for each type of defect, the entropy change associated with the formation of cation vacancy $\Delta S^{0}$ is -11.1 eu. Combining this value with equation (9), $\Delta S^{*}=+44.2$ eu.

According to Zener (ref. 21), a positive value for $\Delta S^{*}$ indicates lattice diffusion, while a negative value for $\Delta S^{*}$ indicates grain boundary diffusion. Therefore it is prob-

${ }^{\mathrm{a}} \mathrm{A}$ silver to silver jump distance of $2.86 \times 10^{-8} \mathrm{~cm}$ (ref. 23) is used. This value is confirmed for $\mathrm{Ag}_{2} \mathrm{~F}$; it is an assumption when applied to $\mathrm{AgF}_{2}$. 
able that the reaction, assuming it is controlled by cation movement, takes place through lattice diffusion. Without further definitive solid-state data on silver difluoride, it is difficult to determine preferential control by either cations or anions. If we assume that the silver difluoride is similar to the other silver halides, then we can say that the most favored mechanism is cation diffusion through a vacancy path. Data are available in the literature for the diffusion coefficient of silver in all of the halides except the fluoride. From the experimental data presented herein, it is possible to calculate a diffusion coefficient for silver ion in $\mathrm{AgF}_{2}$.

\section{Diffusion Coefficient}

The diffusion constant

$$
\mathrm{D}=\mathrm{D}_{\mathrm{O}} \mathrm{e}^{-\Delta \mathrm{H} / \mathrm{RT}}
$$

is estimated as follows: First, the diffusion constant $D_{0}$ is obtained from the DushmanLangmuir equation (ref. 26),

$$
\mathrm{D}_{\mathrm{O}}=\frac{\mathrm{H} \lambda^{2}}{\mathrm{~N}_{\mathrm{O}} \mathrm{H}}
$$

where

$\mathrm{H}$ actiration energy, $4.1 \times 10^{11} \mathrm{erg} / \mathrm{mole}$

$\mathrm{N}_{\mathrm{o}}$ Avogadro's number, $6.02 \times 10^{23}$

h Planck constant, $6.0 \times 10^{-27} \mathrm{erg}-\mathrm{sec}$

$\lambda \quad$ jump distance, $\sim 3 \times 10^{-8} \mathrm{~cm}$

This gives a value of $D_{0}=0.10 \mathrm{~cm}^{2} / \mathrm{sec}$. Then using the previously calculated value of 10 kilocalories per mole $(41.8 \mathrm{~kJ} / \mathrm{mole})$ for $\Delta \mathrm{H}$, a curve of the diffusion coefficient $\mathrm{D}$ against the reciprocal temperature can be plotted as shown in figure 9 .

Table IV lists the diffusion coefficients for silver chloride (ref. 27), bromide (ref. 20), and iodide (ref. 20), as well as the calculated value for silver difluoride at comparable temperature. 


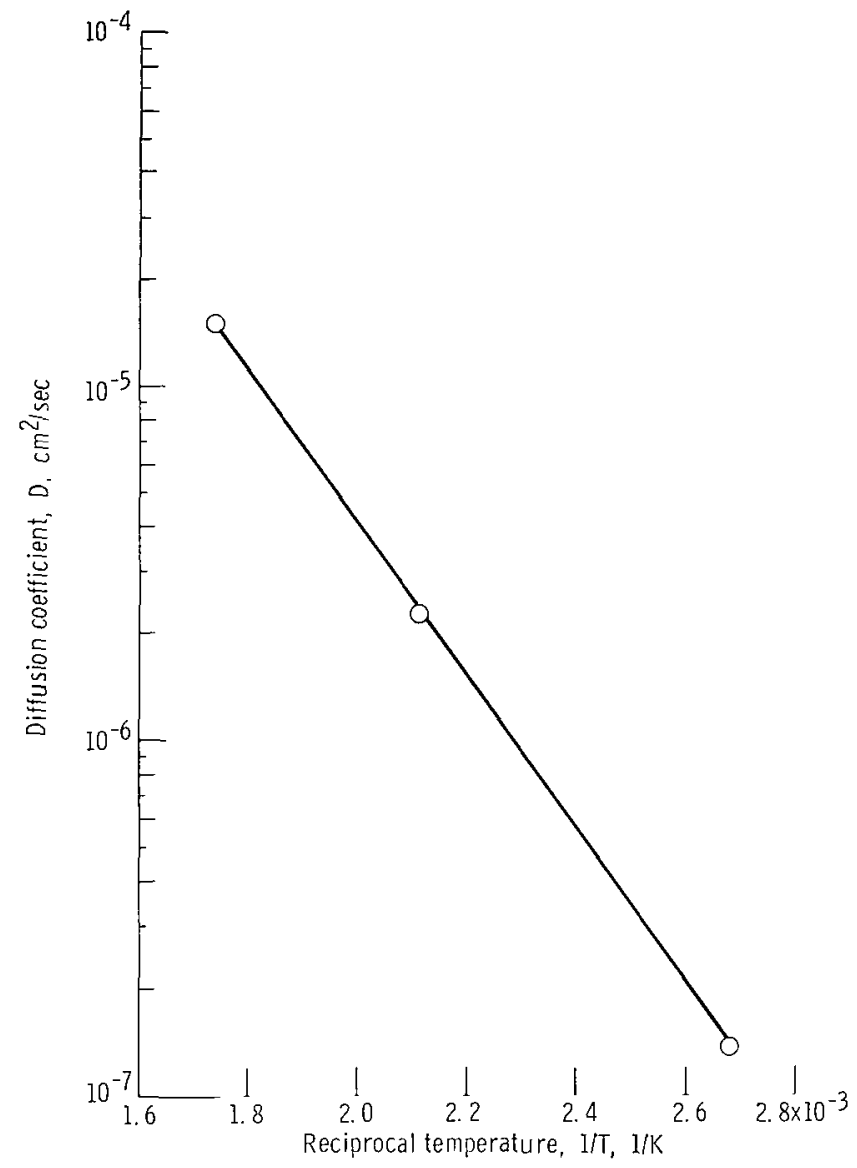

Figure 9. - Diffusion coefficient as function of temperature.

TABLE IV. - DIFFUSION COEFFICIENTS FOR

\section{SILVER HALIDES}

\begin{tabular}{|c|c|c|}
\hline Silver in - & $\begin{array}{c}\text { Diffusion coefficient, } \\
\text { D } \\
\mathrm{cm}^{2} / \mathrm{sec}\end{array}$ & $\begin{array}{c}\text { Temperature, } \\
\mathrm{K}\end{array}$ \\
\hline $\mathrm{AgF}_{2}$ & $5 \times 10^{-6}$ & 511 \\
\hline $\mathrm{AgCl}$ & $1 \times 10^{-9}$ & 511 \\
\hline $\mathrm{AgBr}$ & $5 \times 10^{-8}$ & 511 \\
\hline AgI & $3 \times 10^{-5}$ & 573 \\
\hline
\end{tabular}




\section{CONCLUDING REMARKS}

The reaction between fluorine and silver at temperatures from $25^{\circ}$ to $300^{\circ} \mathrm{C}$ ( 298 to $573 \mathrm{~K}$ ) and $\mathrm{F}_{2}$ pressures of 50 to 600 torr $\left(6666\right.$ to $79993 \mathrm{~N} / \mathrm{m}^{2}$ ) is a complex reaction due to the formation of several products. The three products observed are silver subfluoride $\left(\mathrm{Ag}_{2} \mathrm{~F}\right)$, silver monofluoride $(\mathrm{AgF})$, and silver difluoride $\left(\mathrm{AgF}_{2}\right)$. They are formed in a layered configuration with the one richest in fluorine at the gas-fluoride interface. The kinetics are not simple but must take into account formation rates for each of these species, as well as decomposition rates for the less stable species. The overall rate of the complex reaction has been presented; special treatment to determine individual specific rates were not attempted. The evidence presented points to the conclusion that both boundary and diffusion control play an important part in the reaction.

The reaction has been analyzed in two parts: boundary region and diffusion region. The applicable equation is $y^{n}=k_{r} t+c$. Initially, in the boundary region $n$ has a value of 1 , indicating direct access of gas to the reacting metal surface. As a barrier layer builds up, the reaction becomes diffusion controlled and the value of $n$ equals 2 .

Analysis of the data indicates that the reaction is probably controlled by silver ion migration through the barrier layer. The most probable mechanism for the silver ion migration is a vacancy mechanis $m$. The effect of temperature on the reaction follows a simple Arrhenius-type behavior. However, the pressure effect is not simple. The activation energy is low by oxidation reaction standards but is of the same order of magnitude as other fluorination reactions.

Lewis Research Center,

National Aeronautics and Space Administration, Cleveland, Ohio, January 27, 1970, 120-34.

\section{REFERENCES}

1. Brown, P. E.; Crabtree, J. M. ; and Duncan, J. F.: The Kinetics of the Reaction of Elementary Fluorine with Copper Metal. J. Inorg. Nucl. Chem., vol. 1, 1955, pp. 202-213.

2. O'Donnell, Patricia M.; and Spakowski, A. E.: The Fluorination of Copper. J. Electrochem. Soc., vol. 111, no. 6, June 1964, pp. 633-636.

3. O'Donnell, Patricia M.; and Spakowski, Adolph E.: Reaction of Copper and Fluorine from $800^{\circ}$ to $1200^{\circ} \mathrm{F}$. NASA TN D-768, 1961 . 
4. Steunenberg, R. K. ; Seiden, L.; and Griffen, H. E.: The Reaction of Fluorine with Nickel Surfaces. Chemical Engineering Division Summary Report for July, August, September 1958. Rep. ANL-5924, Argonne National Lab., Dec. 1958, pp. 42-43.

5. Steindler, M. J.; and Steidl, D. V.: Fluorination Rates of Metallic Titanium. Chemical Engineering Division Summary Report for January, February, March 1959. Rep. ANL-5996, Argonne National Lab., June 1959, pp. 135-139.

6. O'Donnell, Patricia M.: Kinetics of the Fluorination of Iron. J. Electrochem. Soc., vol. 114, no. 3, Mar. 1967, pp. 218-221.

7. Anon.: Reaction of Tungsten Metal and Fluorine Gas. Kogyo Kagakw Zasshi, vol. 65, no. 8, Aug. 1962, pp. 1165-1168.

8. Kuriakose, A. K.; and Margrave, J. L.: Kinetics of Reaction of Elemental Fluorinaine. III. Fluorination of Silicon and Boron. J. Phys. Chem., vol. 68, no. 9, Sept. 1964, pp. 2671-2675.

9. O'Donnell, Patricia M.: The Kinetics of the Fluorination of Beryllium. J. Electrochem. Soc., vol. 114, no. 12, Dec. 1967, pp. 1206-1209.

10. Steindler, M. J.; Steidl, D. V.; and Steunenberg, R. K.: The Fluorination of Plutonium Tetrafluoride. Rep. ANL-5874, Argonne National Lab., June 1958.

11. Steunenberg, R. K.; and Fisher, J.: Fluorination Rates of Uranium Tetrafluoride by Mixtures of Fluorine and Helium. Chemical Engineering Division Summary Report for January, February, and March 1959. Rep. ANL-5996, Argonne National Lab. , June 1959, pp. 134-135.

12. Kuriakose, A. K.; and Margrave, J. L.: Kinetics of the Reactions of Elemental Fluorine with Zirconium Carbide and Zirconium Diboride at High Temperatures. J. Phys. Chem., vol. 68, no. 2, Feb. 1964, pp. 290-295.

13. Kuriakose, A. K. ; and Margrave, J. L.: Kinetics of Reaction of Elemental Fluorine. II. The Fluorination of Hafnium Carbide and Hafnium Boride. J. Phys. Chem., vol. 68, no. 8, Aug. 1964, pp. 2343-2345.

14. Ritter, Robert L.; and Smith, Hilton A.: The Kinetics and Mechanism of Flurination of Copper Oxide. II. The Reaction of Fluorine with Copper (I) Oxide. J. Phys. Chem., vol. 71, no. 7, June 1967, pp. 2036-2043.

15. Hudson, Derek, J.: Fitting Segmented Curves Whose Join Points Have to be Estimated. J. Amer. Stat. Assoc., vol. 61, no. 316, Dec. 1966, pp. 1097-1129.

16. Kubaschewski, O.; and Hopkins, B. E.: Oxidation of Metals and Alloys. Second ed., Butterworths Sci. Publ., 1962, pp. 36-45. 
17. Evans, Ulick R.: The Corrosion and Oxidation of Metals: Scientific Principles and Practical Applications. St. Martin's Press, 1960, pp. 767-859.

18. Ruff, Otto; and Giese, Manfred. The Fluorination of Silver and Copper. Z. anorg. allgen. Chem., vol. 219, 1934, pp. 143-148.

19. Pilling, N. B.; and Bedworth, R. E. : The Oxidation of Metals at High Temperatures. J. Inst. Metals, vol. 29, 1923, pp. 521-591.

20. Jost, Wilhelm: Diffusion in Solids, Liquids, Gases. Academic Press, Inc., 1960.

21. Zener, Clarence: Theory of $\mathrm{D}_{\mathrm{O}}$ for Atomic Diffusion in Metals. J. Appl. Phys., vol. 22, no. 4, Apr. 1951, pp. 372-375.

22. Gulbransen, E. A.: The Transition-State Theory of the Formation of Thin Oxide Films on Metals. Trans. Electrochem. Soc., Vol. 83, 1943, pp. 301-313.

23. Moeller, Therald, ed. Inorganic Synthesis. Vol. 5. McGraw-Hill Book Co., Inc., 1957, pp. 18-21.

24. Gulbransen, Earl A.; and Andrew, Kenneth F.: Oxidation of Zirconium Between $400^{\circ}$ and $800^{\circ}$ C. J. Metals, vol. 9, no. 4, Apr. 1957, pp. 394-400.

25. McBride, Bonnie J.; Heimel, Sheldon; Ehlers, Janet G. ; and Gordon, Sanford: Thermodynamic Properties to $6000^{\circ} \mathrm{K}$ for 210 Substances Involving the First 18 Elements. NASA SP-3001, 1963.

26. Dushman, Saul; and Langmuir, Irving: The Diffusion Coefficient in Solids and its Temperature Coefficient. Phys. Rev., vol. 20, 1922, p. 113.

27. Compton, W. Dale: Self-Diffusion and Conductivity in Silver Chloride. Phys. Rev., vol. 101, no. 3, Feb. 1, 1956, p. 1209-1210. 


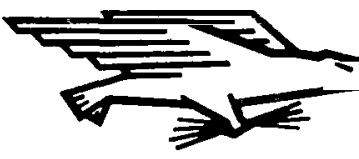

POSTAGE AND FEES PAID NATIONAL AERONAUTICS A SPACE ADMINISTRATION

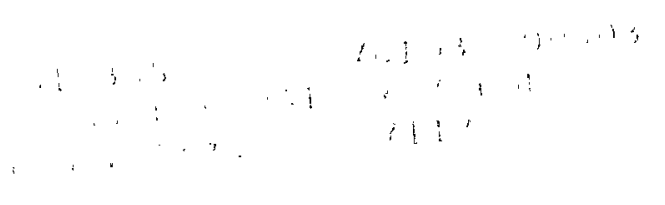

"The aeronantical and space activities of the United States sball be conducted so as to contribute. . . to the expansion of buman knouledge of pbenomena in the atmospbere and space. The Administration shall provide for the widest practicable and appropriate dissemination of information concerning its activities and the results thereof."

- National Aeronautics and Space ACt of 1958

\section{NASA SCIENTIFIC AND TECHNICAL PUBLICATIONS}

TECHNICAL REPORTS: Scientific and technical information considered important, complete, and a lasting contribution to existing kṇowledge.

TECHNICAL NOTES: Information less broad in scope but nevertheless of importance as a contribution to existing knowledge.

\section{TECHNICAL MEMORANDUMS:}

Information receiving limited distribution because of preliminary data, security classification, or other reasons.

CONTRACTOR REPORTS: Scientific and technical information generated under a NASA contract or grant and considered an important contribution to existing knowledge.
TECHNICAL TRANSLATIONS: Information published in a foreign language considered to merit NASA distribution in English.

SPECIAL PUBLICATIONS: Information derived from or of value to NASA activities. Publications include conference proceedings, monographs, data compilations, handbooks, sourcebooks, and special bibliographies.

\section{TECHNOLOGY UTILIZATION}

PUBLICATIONS: Information on technology used by NASA that may be of particular interest in commercial and other non-aerospace applications. Publications include Tech Briefs, Technology Utilization Reports and Notes, and Technology Surveys.

Details on the availability of these publications may be obtained from:

SCIENTIFIC AND TECHNICAL INFORMATION DIVISION 